\title{
Contact fatigue failure modes of HVOF coatings
}

\author{
R. Ahmed* \\ Department of Mechanical and Chemical Engineering, Heriot-Watt University, Riccarton, Edinburgh EH14 4AS, UK \\ Received 28 November 2001; received in revised form 23 May 2002; accepted 23 May 2002
}

\begin{abstract}
The objective of this experimental study was to investigate the influence of coating thickness and contact stress fields on the performance and fatigue failure modes of thermal spray (WC-12\% Co) HVOF coatings. Results of this study indicate that a non-dimensional coating thickness parameter $(\Delta=\xi / \Psi)$, where $\xi$ is the coating thickness and $\Psi$ the depth of maximum shear stress, can be used as a useful index to optimise coating delamination resistance during Hertzian contact loading. Apart from the detection of a new failure mode (termed spalling), which is a rare failure mode in thermal spray coatings, results indicate that by appropriate control of coating thickness, and tribological conditions, it is possible to achieve a fatigue life in excess of 70 million stress cycles, without failure. This improvement in coating performance was attributed to improved fracture toughness of liquid fuel HVOF (JP5000) coatings. Coating failure was attributed to micro- and macrocracking within the coating microstructure. Thermal spray coatings were deposited by a JP5000 system in three different thicknesses on the surface of 440-C steel substrate cones to vary the depth of shear stress within the Hertzian stress field. Rolling contact fatigue (RCF) tests were conducted using a modified four-ball machine under various tribological conditions of contact stress, configuration and lubrication. Surface observations were made using scanning electron microscope (SEM), surface interferometry and light microscopy, whereas subsurface observations were made using die penetrant investigations.
\end{abstract}

(C) 2002 Elsevier Science B.V. All rights reserved.

Keywords: HVOF coatings; Hertzian stress field; Rolling contact fatigue; Failure modes

\section{Introduction}

Continuous advancements and enhanced understanding of thermal spray technology has facilitated a synergetic approach towards a sustainable growth of its industrial applications. This has enabled designers to push the frontiers of tribological applications of these overlay coatings, far beyond, to what was perceived a decade ago. Driven by the economics of surface engineering industry and, coupled with the environmental friendly and coating restoration (worn and undersized components) aspect, one area of such continuous development has been the durability of sprayed coatings in rolling sliding contacts. Albeit advancements in thermal spraying technology, especially in the area of powder production, coating processes and optimization of deposition conditions, studies relating to a generic approach for tribological design are limited. Recently, studies have

Abbreviations: APS, air plasma spray; BEI, backscattered electron image; EHL, elasto-hydrodynamic lubrication; HPP, hydraulic pressure propagation; HVOF, high velocity oxy-fuel; HV, hardness (Vickers); RCF, rolling contact fatigue; RMS, root mean square; SEM, scanning electron microscopy

* Tel.: +44-0131-449-5111; fax: +44-0131-451-3129

E-mail address: r.ahmed@hw.ac.uk (R. Ahmed). addressed some of the tribological issues relating to the design of thermally sprayed components [1-4] and indicated that a synergetic experimental and theoretical approach can enable optimal tribological design in rolling sliding contacts. This paper reports the results of an experimental approach adapted to investigate the performance of WC cermet coatings deposited by a HVOF (JP5000) system to deliver a semi-empirical design approach. The aim of this investigation was to comprehend the performance and distinguish contact fatigue failure modes for the HVOF (JP5000) liquid fuel system, and compare them to previously reported investigation on air plasma sprayed (APS) coatings [3]. Work presented here shows a step forward in understanding the failure mechanisms of these coatings and provides a feedback approach for optimising the design of surface engineered components.

\section{Experimental test procedure}

\subsection{Coating deposition}

A liquid fuel HVOF (JP5000) system was used to deposit WC-12\%Co coatings on the surface of 440-C steel 


\begin{tabular}{|ll|}
\hline \multicolumn{2}{|l|}{ Nomenclature } \\
$a$ & major axis of the contact ellipse \\
$b$ & minor axis of the contact ellipse \\
$F$ & contact force \\
$H_{\mathrm{min}}$ & minimum film thickness \\
$M$ & mass at the end of lever arm \\
$P_{\mathrm{O}}$ & peak compressive stress \\
$R$ & lever arm ratio $(20: 1)$ \\
$R_{\mathrm{qd}}$ & root mean square surface roughness \\
& of drive coated cone \\
$R_{\mathrm{qp}}$ & root mean square surface roughness of \\
& driven planetary ball \\
$T_{\mathrm{max}}$ & maximum tensile stress \\
& \\
$G r e e k$ & letters \\
$\beta$ & ratio of minor to major axis of contact ellipse \\
$\Delta$ & non-dimensional coating thickness $(\xi / \Psi)$ \\
$\theta$ & contact angle $\left({ }^{\circ}\right)$ \\
$\lambda$ & non-dimensional film thickness \\
$\xi$ & average coating thickness \\
$\tau_{\text {max }}$ & maximum shear stress \\
$\Psi$ & depth of maximum shear stress \\
$\omega$ & spindle speed (rpm) \\
\hline
\end{tabular}

rolling element cones. This system was selected because of its higher particle velocities, which are in the range $1005-1118 \mathrm{~m} \mathrm{~s}^{-1}$ and a more uniform distribution of particles within the spray stream, resulting in better coating quality [5]. The coating and substrate materials were selected because of their desired combination of mechanical and thermal properties. The substrate rolling element cones were $14.5 \mathrm{~mm}$ in diameter and had an apex angle of $109.4^{\circ}$. The spraying direction was perpendicular to the apex of the cone. The spraying arrangement comprised of six spray guns inclined at an approximate angle of $70^{\circ}$ to the plane of the rotating plate, which contained the rolling element cones. Although this was a more complex arrangement than conventionally used techniques, i.e. to spray individual cones along the direction of cone axis, this technique had the advantage to allow sufficient cooling to avoid substrate overheating, whilst spraying almost normal to the cone apex to avoid shadowing effects. The HVOF process conditions, which were industrially optimised for this spray system to produce a dense $\mathrm{WC}-12 \% \mathrm{Co}$ coating microstructure with minimum carbon loss, were used in this study. Prior to the spraying process, the substrate material was sandblasted and preheated to a temperature range $100-150^{\circ} \mathrm{C}$. The average as-sprayed coating thickness of the rolling element cones were 300, 200 and $100 \mu \mathrm{m}$. These rolling element cones were ground and polished to give an average coating thickness $(\xi)$ of $235 \pm 15,150 \pm 15$ and $60 \pm 10 \mu \mathrm{m}$, respectively.

\subsection{Rolling contact fatigue tests}

A modified four-ball machine shown in Fig. 1 was used to conduct the rolling contact fatigue (RCF) tests to comprehend the performance of thermally sprayed rolling element cones. This modification not only allowed the rotation of the

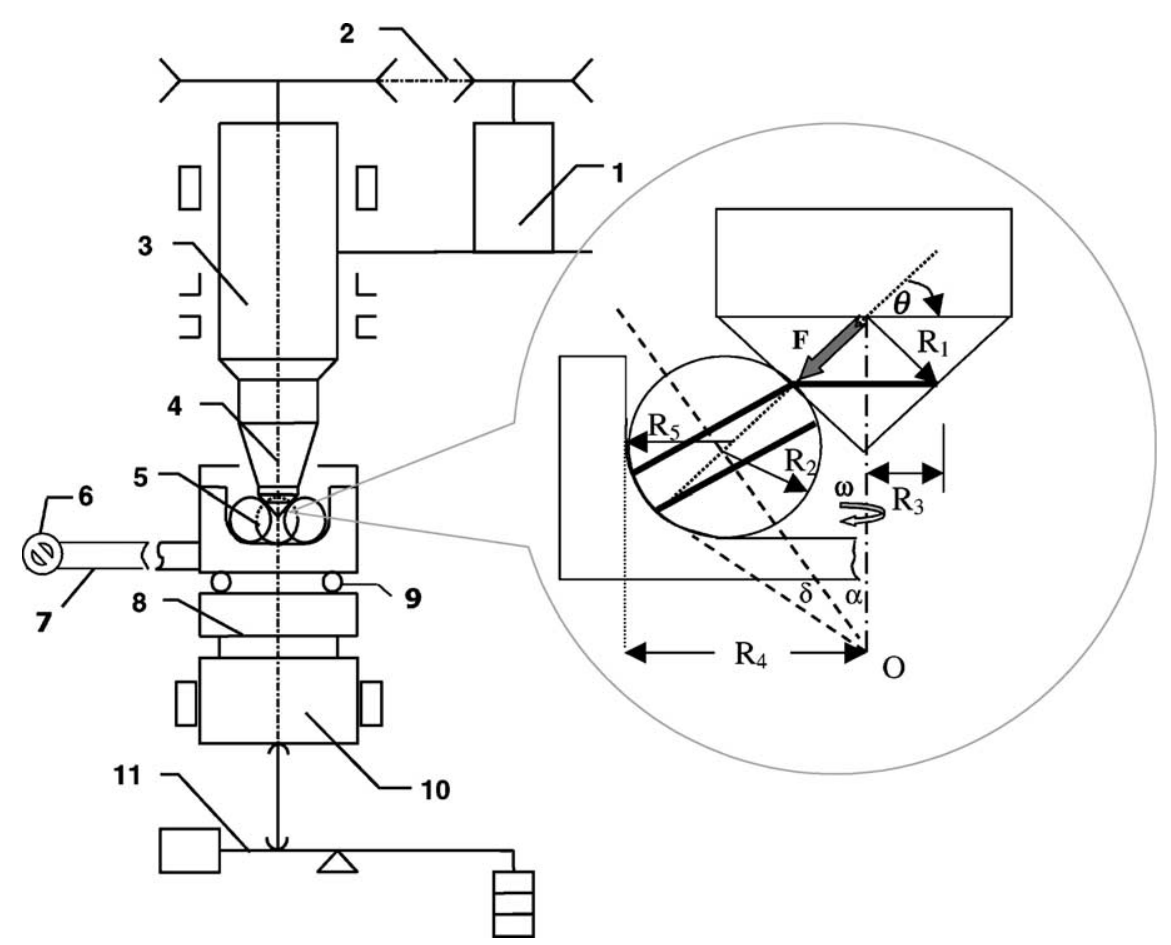

Fig. 1. Schematic of the modified four-ball machine. $R_{1}=R_{2}=6.35 \mathrm{~mm}, R_{3}=3.65 \mathrm{~mm}, R_{4}=14.2 \mathrm{~mm}, R_{5}=7.62 \mathrm{~mm}, \theta=35.15^{\circ}, \delta=25.33^{\circ}$, $\alpha=29.52^{\circ}, \omega=4000 \pm 10 \mathrm{rpm}$. 1: Driving motor; 2: belt drive; 3: spindle; 4: coated cone and collet; 5: cup assembly; 6: force transducer; 7: torque arm; 8: heater; 9: thrust bearing; 10: loading piston and 11: loading lever. 
Table 1

Properties of test lubricant

\begin{tabular}{|c|c|c|c|c|c|}
\hline \multirow[t]{2}{*}{ Lubricant type } & \multirow[t]{2}{*}{ Specific gravity at $15^{\circ} \mathrm{C}$} & \multirow[t]{2}{*}{ Flash point $\left({ }^{\circ} \mathrm{C}\right)$} & \multirow[t]{2}{*}{ Pour point $\left({ }^{\circ} \mathrm{C}\right)$} & \multicolumn{2}{|c|}{ Kinematic viscosity $(\mathrm{cP})$} \\
\hline & & & & $40^{\circ} \mathrm{C}$ & $100^{\circ} \mathrm{C}$ \\
\hline Hitec-174 & 0.95 & 255 & -20 & 200 & 40 \\
\hline Exxon-2389 & 0.955 & 220 & -65 & 12.46 & 3.19 \\
\hline
\end{tabular}

planetary-balls, but also correctly modelled the kinematics of deep groove rolling element bearing, and precisely defined the contact load. In the current investigation, the coated rolling element cone replaced the upper drive-ball, which represented the inner race of the rolling element ball bearing. RCF tests were conducted in type-II configuration, in which planetary balls not only rotate about the axis of shaft rotation, but also are free to spin about an axis inclined at an angle $\beta$ to the axis of shaft rotation. Details of the ball kinematics and roll/spin ratio for various configurations of modified four-ball machine can be seen in papers gathered by Tourret and Wright [6]. As the planetary balls were free to rotate, there was no gross sliding in the modified four-ball assembly. However, there is an element of microslip within the contact region, which can arise from the contact conformity (Heathcote slip), and also the difference in elastic modulus (Reynolds slip) of the contacting bodies. For the tribological conditions used in this investigations, the latter is negligible, whereas, negative slip arising from contact conformity (Heathcote slip) was approximated as 3-4\%. Coated rolling element cones were ground and polished to attain a root mean square (RMS) surface roughness of $0.065 \pm 0.015 \mu \mathrm{m}$ $\left(R_{\mathrm{q}}\right)$. Planetary rolling element balls were commercial grade $12.7 \mathrm{~mm}$ diameter $440-\mathrm{C}$ bearing steel or $\mathrm{Si}_{3} \mathrm{~N}_{4}$ ceramic, having surface roughness of $0.01 \pm 0.005 \mu \mathrm{m}\left(R_{\mathrm{q}}\right)$. These two materials were used to conduct RCF tests in conventional steel ball bearing (steel planetary balls) and hybrid ceramic bearing (ceramic planetary balls) configurations. RCF tests were conducted under immersed lubrication conditions at a spindle speed $(\omega)$ of $4000 \pm 10 \mathrm{rpm}$ and at an ambient temperature of $24^{\circ} \mathrm{C}$. Failure was defined as the increase in vibration amplitude above a pre-set level. Two lubricants, i.e. Hitec-174 and Exxon-2389 were used to vary the lubrication regime during the RCF test. Hitec-174 is a high viscosity hydrocarbon oil whilst Exxon-2389 is a commercially available synthetic oil; properties of both lubricants are given in Table 1 . The ratio $(\lambda)$ of the elasto-hydrodynamic lubricant film thickness to the average surface roughness was calculated using the following relationship:

$\lambda=\left\{\frac{H_{\min }}{\left(R_{\mathrm{qd}}^{2}+R_{\mathrm{qp}}^{2}\right)^{0.5}}\right\}$

where $R_{\mathrm{qd}}$ is the RMS surface roughness of the driving rolling element cone, $R_{\mathrm{qp}}$ the RMS surface roughness of the planetary balls. $H_{\min }$ the minimum film thickness, calculated using the following relationship of hard elasto-hydro- dynamic lubrication [7]:

$H_{\min }=3.63 U^{0.68} G^{0.49} W^{-0.073}\left(1-\mathrm{e}^{-0.68 k}\right)$

where $U$ is the dimensionless speed parameter, $G$ the dimensionless material parameter, $W$ the dimensionless load parameter and, $k$ the dimensionless ellipticity parameter. The $\lambda$ value was approximated as greater than 3 for the Hitec-174 lubricant $(\lambda \approx 4-5)$ indicating a full film regime, whilst less than 3 ( $\lambda \approx 0.6-1$ ) for Exxon-2389 lubricant indicating a mixed lubrication regime, for the test conditions used in this investigation.

Fig. 1 also shows the schematic of the arrangement used to measure the total frictional torque in the modified four-ball assembly. The arrangement consisted of a torque arm protruding from the base of the cup assembly, which contacts a force transducer at the other end in a horizontal plane. The transducer is calibrated before the measurements and measures the frictional force acting at the end of lever arm. The output signal from the force transducer is sent to a digital display and then to a printer. The cup assembly rests on a rolling element thrust bearing. The frictional torque measured represents the sum of the frictional torque in the four-ball cup assembly and the frictional torque due to the rolling element thrust bearing, through which, load is applied to the cup assembly. The frictional torque values were recorded for the entire test duration and the averaged values are indicated in the next section.

\section{Experimental test results}

RCF tests were conducted in a variety of tribological conditions of Hertzian contact stress and configuration. Table 2 summarises typical tribological test conditions and RCF results. These results are not intended for statistical fatigue life prediction, but to comprehend the performance under various tribological conditions of contact stress, configuration and lubrication. Peak compressive stress $\left(P_{\mathrm{o}}\right)$ values listed in Table 2 were based upon the uncoated case of the contacting rolling elements. These stress values were calculated using the following relation:

$P_{\mathrm{o}}=\frac{3 F}{2 \pi a b}$

where $a$ and $b$ are the major and minor axis of Hertzian contact ellipse, which can be calculated from the geometrical dimensions and the values of the Young's modulus and 


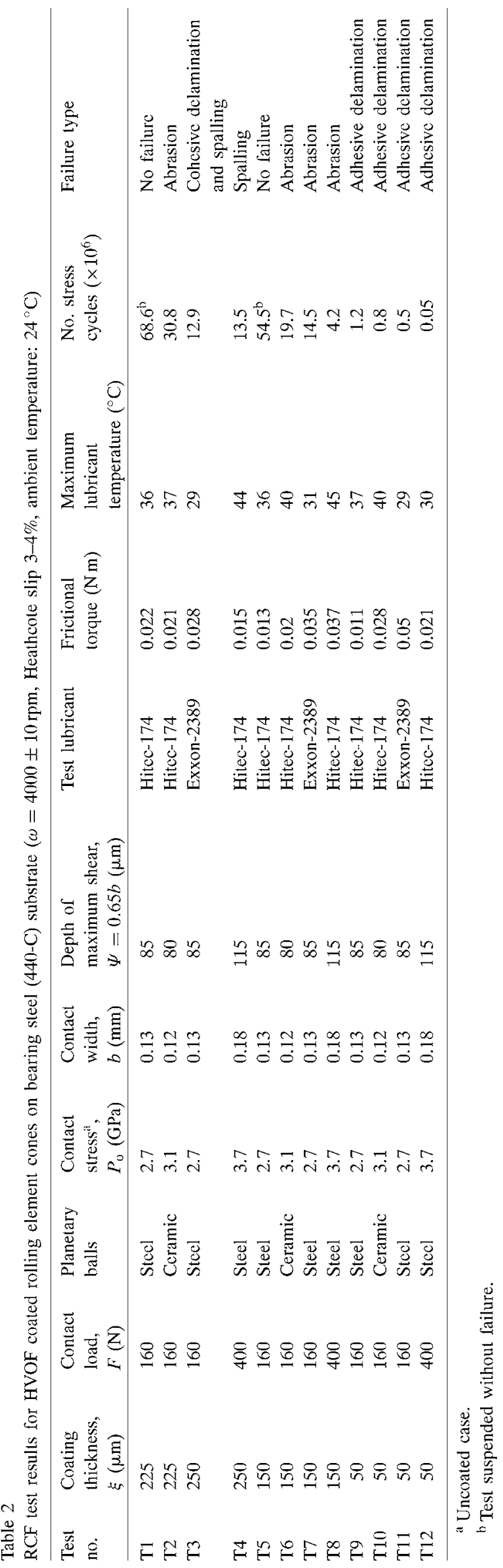


(a)

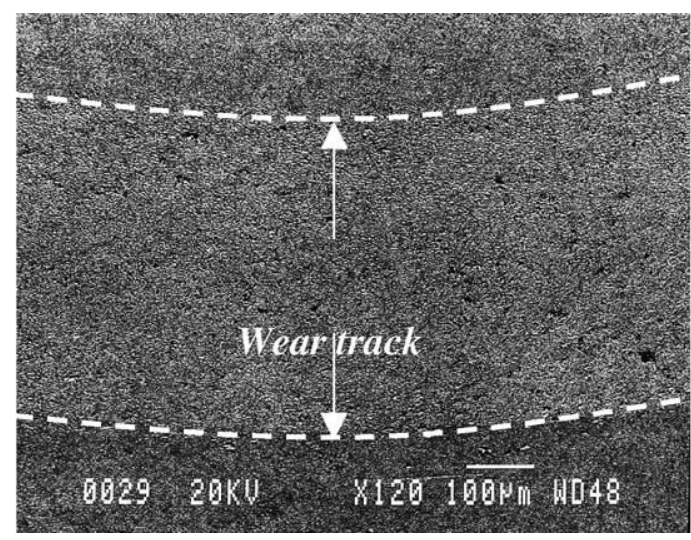

(b)

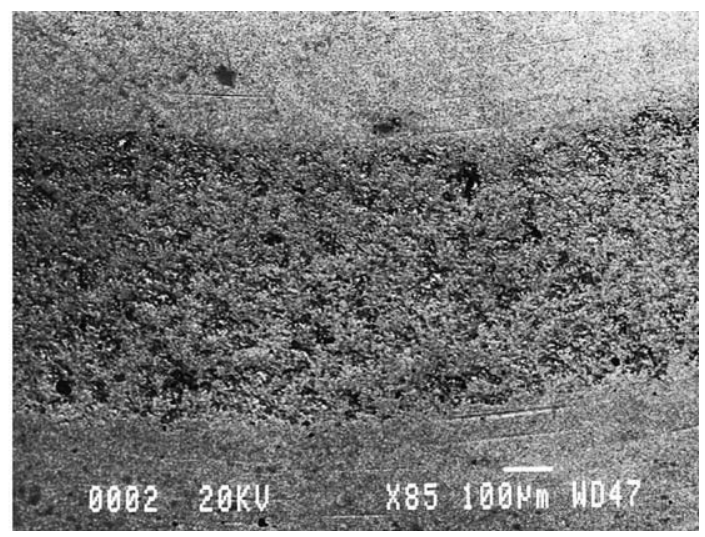

Fig. 2. Surface observations of the wear track after tests. (a) T1 (no failure) and (b) T2 (surface wear).

Poisson's ratio of the contacting rolling elements. The contact force, $F(\mathrm{~N})$, was calculated using the following relation:

$F=\frac{9.8 R M}{3 \cos \theta}$

where $R$ is the lever arm ratio of the modified four-ball machine, set at $20: 1 ; M(\mathrm{~kg})$ the mass at the end of lever arm; $\theta$ the angle of contact between the drive and driven rolling element, calculated as $35.3^{\circ}$. The depth of maximum shear stress $\left(\tau_{\max }\right)$ included in Table 2 was evaluated using the conventional contact mechanics approach [8], reproduced here for clarity:

$\tau_{\max }=0.35 P_{\mathrm{o}}$ at a depth of $0.65 b$

\subsection{Surface observations}

Fig. 2 shows the SEM comparison of the wear tracks of the $225 \mu \mathrm{m}$ thick coated rolling elements subjected to tests $\mathrm{T} 1$ and T2. It can be appreciated from Fig. 2a that there was hardly any wear on the wear track for the suspended test T1. However, appreciable micropitting was observed in the case of test T2 (Fig. 2b). These tests were conducted under similar conditions of contact loading and lubrication, except for contact configuration, which was hybrid ceramic (stiffer and harder) for test $\mathrm{T} 2$. Test conducted under similar tribological conditions, but on $150 \mu \mathrm{m}$ thick coatings followed a trend, similar to what was observed for $225 \mu \mathrm{m}$ thick coated rolling elements (shown in Fig. 2), i.e. wear track of suspended test T5 was similar to Fig. 2 a and showed no failure, whereas that of test T6 showed micropitting, which was similar to that for test T2, as shown in Fig. 2b. In addition to test T2 and T6, some other tests (i.e. T7, T8) also showed a similar micropitting behaviour. For the reasons discussed in Section 4, the failure caused by such micropitting is termed as abrasive failure in Table 2. Three-dimensional surface profilometry of the micropitted wear track (e.g. after test T6) using a light interferometer indicated that the surface damage (micropitting) was up to $10 \mu \mathrm{m}$ deep, as shown in Fig. 3. This figure also shows a two-dimensional line trace profile at the dotted section in the three-dimensional plot. Hence, micropitting seen in abrasive failure was confined to the near surface region of approximately $10 \mu \mathrm{m}$ depth. Fig. $4 \mathrm{a}$ shows the failed area on the wear track of the coated rolling element subjected to test T3. The depth of this failure at the cliff-edge was approximated as $50 \mu \mathrm{m}$, whereas deeper cracks existed, as was confirmed during subsurface observations (next section). Fig. 4b shows crack lip in the middle of wear track across the rolling direction, which extends slightly (by approximately $100 \mu \mathrm{m}$ ) beyond the width of the wear track. Fig. 5a shows the failed area of the wear track after test T4, whereas Fig. 5b shows another failure within the wear track. Fig. 6a shows the back-scattered electron image (BEI) of the delaminated wear track of the coated rolling element subjected to test T11. It can be appreciated from the BEI that the coating failure was due to delamination at the coating substrate interface (adhesive), resulting in sheet-like debris as shown in Fig. 6b. Failures observed in all the cases of RCF tests conducted on rolling elements of $50 \mu \mathrm{m}$ average coating thickness (i.e. tests T9-T12) were similar to that shown in Fig. 6, i.e. delamination at the coating substrate interface, and not shown here to avoid repeatability.

\subsection{Subsurface observations}

Subsurface observations of coated rolling elements are critical in identifying the crack propagation mechanisms, either within the coating microstructure, or at the coating substrate interface. Die penetrant investigations in combination with ultraviolet light microscopy were thus conducted by progressive grinding of the wear track. The use of die penetrant ensured that the cracks identified were caused during the fatigue failure and not a post-failure sectioning damage, whereas progressive grinding ensured that damage during material removal was be kept to a minimum. Details of this technique, as applied to thermal spray coatings, can be appreciated from Ahmed and Hadfield [3]. Fig. 7 shows typical observations from this investigation for the coated rolling element cone subjected to test T3. Fig. 7a shows the crack identified by the die penetration at an approximate depth of 

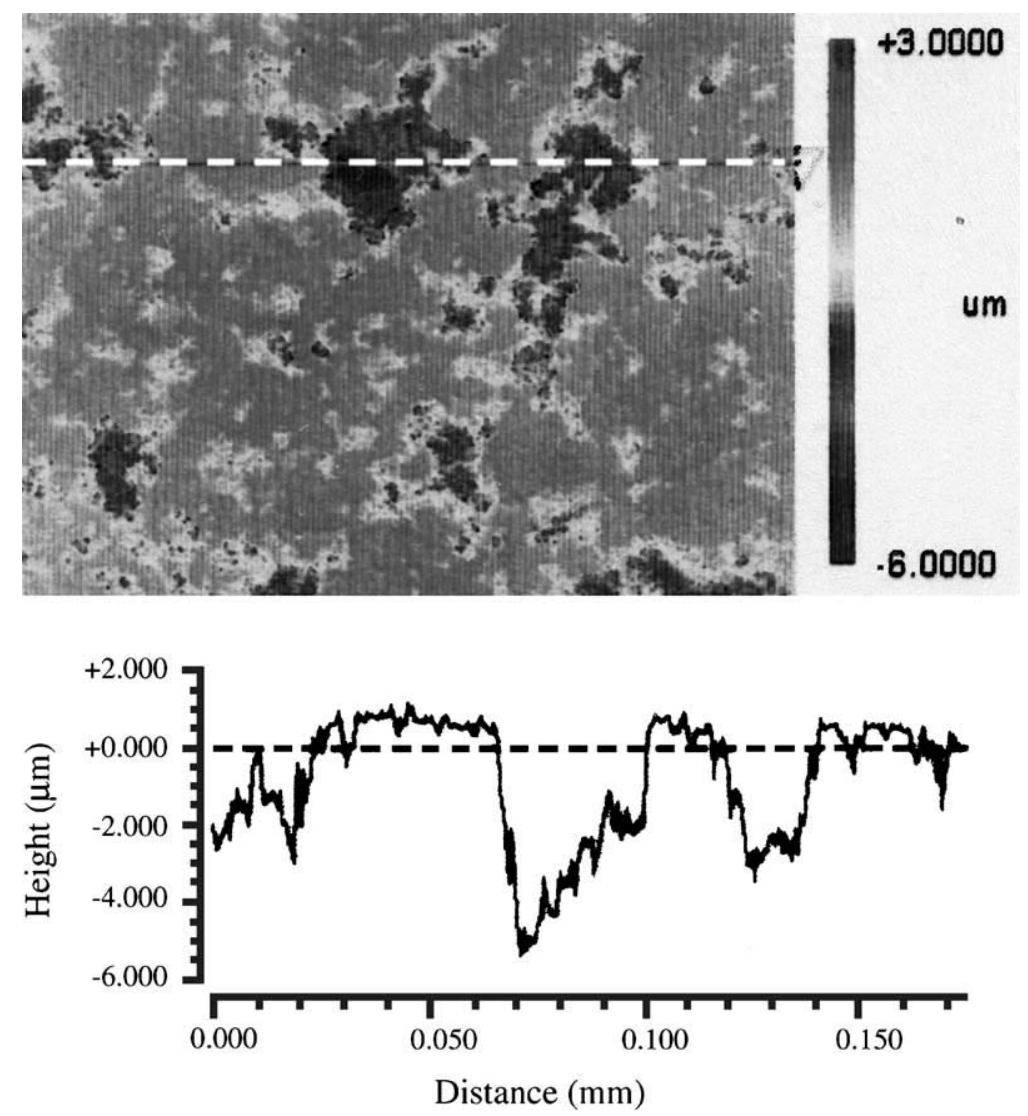

Fig. 3. Two- and three-dimensional surface profilometry results within the wear track after test T6.

$100 \mu \mathrm{m}$. This crack was identified at the edge of the wear track. As progressive grinding into the wear track continued, the exact crack length was identified as approximately $1.5 \mathrm{~mm}$, which joined the delaminated area (Fig. 7b). As it was now confirmed that the identified crack originated during the fatigue test and not caused by the sectioning process, SEM observation of the entire section was made as shown in Fig. 7c. Fig. 7d shows a taper section across the wear track at higher magnification, due to which coating appears thicker than $250 \mu \mathrm{m}$, but indicates three-dimensional nature of subsurface cracks. It is, however, important to appreciate at this stage that, for the coatings thicker than $50 \mu \mathrm{m}$ (i.e. tests T1-T8), except for the observations shown in Fig. 7 for test T3, there was no evidence of subsurface cracking during the subsurface (die penetrant) investigations.

\subsection{Microhardness measurements}

A Vickers hardness tester was used to measure the microhardness of rolling elements. Microhardness measurement of thermally sprayed cones indicated that the average microhardness of the coating material $\left(\mathrm{HV}_{300}\right)$ was 1296 , whereas the average microhardness of the substrate material $\left(\mathrm{HV}_{100}\right)$ was 728 . These values were averaged after neglecting the highest and the lowest values. Hardness measurements for the steel and ceramic planetary balls indicated a Vickers hardness of 850 and 1600, respectively.

Attempts were also made to measure the indentation fracture toughness of thermal spray coatings using the indentation technique [9]. A surprising result was that these HVOF (JP5000) coatings did not crack at indentation loads as high as $4.9 \mathrm{~N}(500 \mathrm{p})$. Out of 10 indentations at a load of $4.9 \mathrm{~N}$ and 15 indentations at an indentation load of $2.9 \mathrm{~N}$ (300p) only one indentation cracked. Fig. 8a shows an overall view of these indentations across the coating thickness at two loads, whereas Fig. 8b shows a magnified view of indentation at a load of $4.9 \mathrm{~N}$, confirming the absence of cracks. It was appreciated from this qualitative analysis that these coatings had an improved indentation fracture toughness in comparison to the coatings deposited by APS and other conventional HVOF processes, which showed intense microcracking even at lower load of $2.9 \mathrm{~N}$. Fig. 8c represent one such observation for APS WC-12\%Co coating, reported earlier and reproduced here for clarity [3]. Fig. 8c shows that even at relatively lower loads of $2.9 \mathrm{~N}$ (in comparison to 4.9 for JP5000 coatings), APS coatings cracked readily under the indentation load, indicating relatively poor toughness of APS coatings. As JP5000 coatings used in the current investigation did not show any cracks originating from the indentation diagonal, it was not possible to quantitatively evaluate the values 


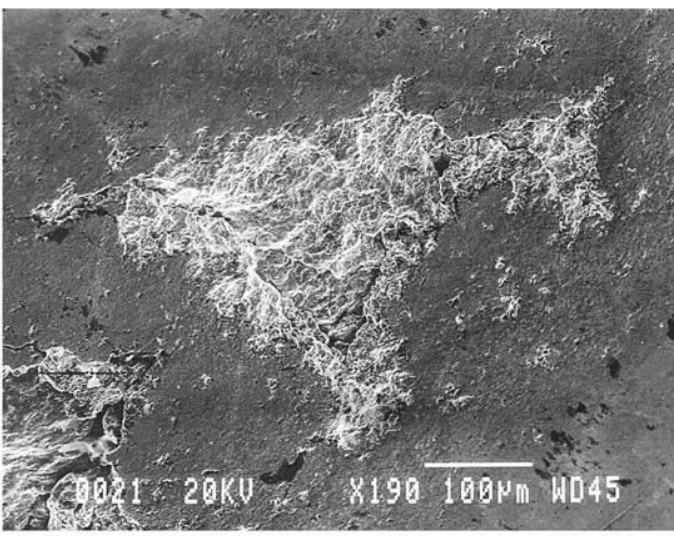

(a) Failed area

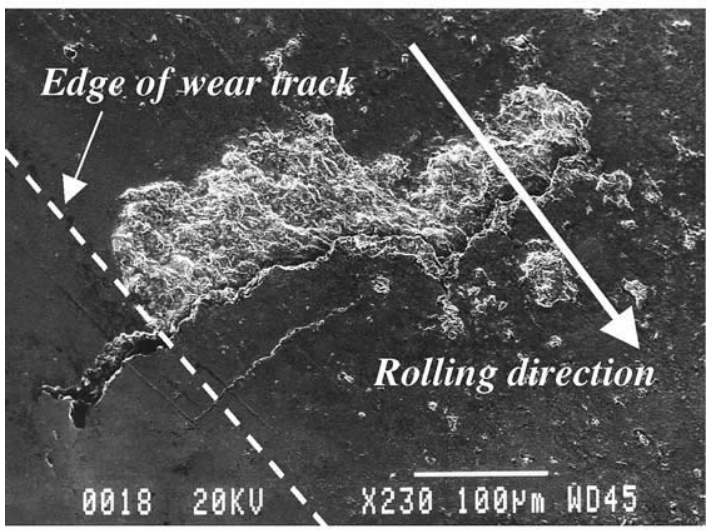

(b) Cracks extending across the wear track

Fig. 4. SEM observations of the surface of wear track after test T3. (a) Failed area and (b) cracks extending across the wear track.

of indentation fracture toughness $\left(K_{1 \mathrm{c}}\right)$ and the critical strain energy release rate $\left(G_{\mathrm{c}}\right)$ using this technique. Although other techniques for a quantitative measure of fracture toughness in thermal spray coatings exist, they did not form a part of current study, as the results are generally subjective to the test method used, i.e. not normally comparable for various techniques. Readers are referred to Lin and Berndt [9] for a detailed comparison of various available techniques. However, a qualitative comparison between APS and JP5000 (HVOF) coatings can be made by comparing Fig. $8 \mathrm{a}$ and b with $\mathrm{c}$.

In addition to the microhardness and fracture toughness analysis, universal microhardness was used to perform Young's modulus measurements on flat disc (WC-12\%Co) coated test samples sprayed by the JP5000 system. Although the measurement of Young's modulus in thermal spray coatings is subjective to the test method used, this method was particularly suited to the small-sized specimen used in this study. Indentation method of modulus measurement relies on the real time elastic plastic response of force-displacement (indentation) curve, details of which can be seen elsewhere [10]. In the case of $\mathrm{WC}-12 \% \mathrm{Co}$ coated JP5000 coatings, these investigations were made at an indentation load of $1 \mathrm{~N}$, i.e. a load which was found to produce reproducible results. Results of this analysis indi-

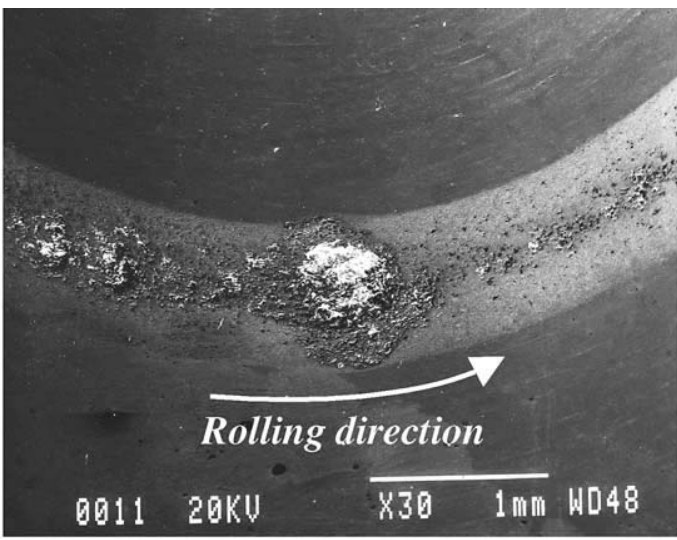

(a) Spall type failure

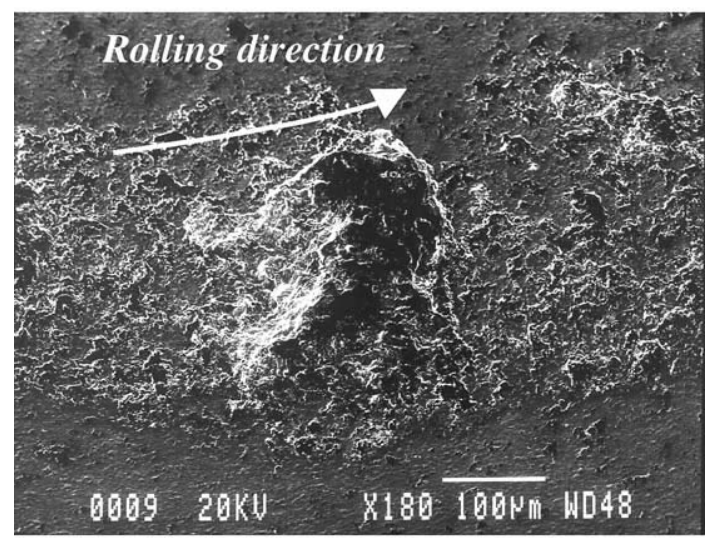

(b) Failure within the wear track

Fig. 5. SEM observations of the surface of wear track after test T4. (a) Spall type failure and (b) failure within the wear track.

cated that the average value of Young's modulus of JP5000 (WC-12\%Co) coatings was $231 \pm 17 \mathrm{GPa}$.

\section{Discussion}

\subsection{Failure modes}

The principal aim of this investigation was to investigate the RCF performance and failure modes of recently developed liquid fuel HVOF systems of superior coating microstructure [5] and fracture toughness (Fig. 8), and compare them to previously reported investigation on APS coatings [3]. Such analysis was critical in providing a feedback loop for optimising coating performance and deliver semi-empirical design approach to combat contact fatigue failures in thermal spray coatings. Previous studies relating to RCF failure modes of APS coatings indicated that three distinct modes of fatigue failure, i.e. cohesive delamination, adhesive delamination and abrasion can lead to coating failure in rolling contacts [3]. There, the term cohesive delamination was defined as the delamination within the coating microstructure, whereas adhesive delamination was defined as the delamination at the coating substrate interface. 


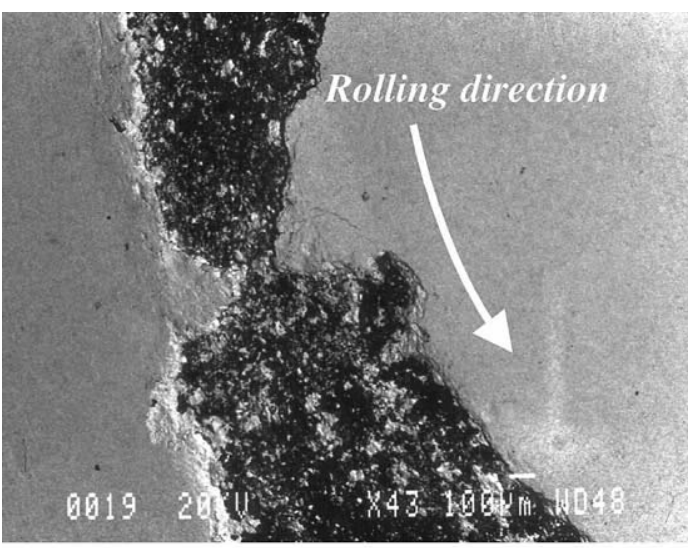

(a) Interfacially delaminated wear track

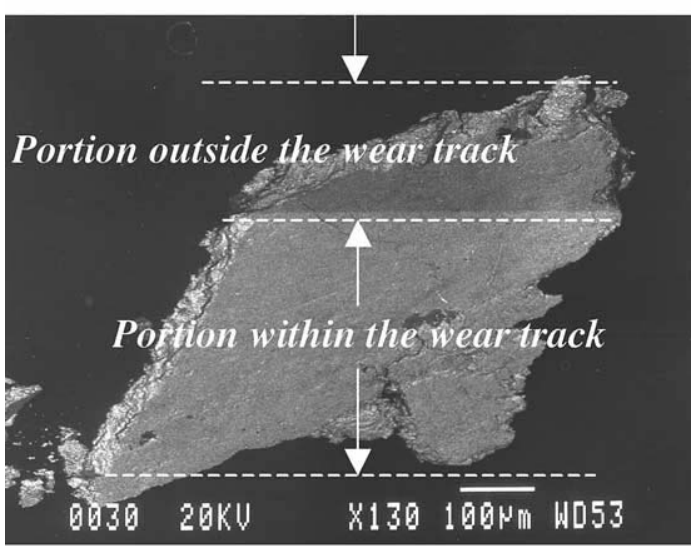

(b) Delaminated debris

Fig. 6. SEM observations after test T11. (a) Interfacially delaminated wear track and (b) delaminated debris.

Similarly, abrasive failure was defined as the failure caused by miropitting on the surface of wear track. In the current investigation, the definition of these terminologies remains the same.

\subsubsection{Cohesive delamination}

Fig. 9 shows a detailed version of the schematic of coating delamination process reported earlier for APS coatings [3]. Although the details of investigations shown in Fig. 9 can be seen in [3], the figure is included here to aid the discussion. For APS coatings, it was argued that coating delamination results from delamination cracks, parallel to contact surface, and at the depth of orthogonal and maximum shear stress. These cracks originate from stress concentrations (due to microdefects) within the coating microstructure and at the coating substrate interface. In comparison to APS coatings, JP5000 (HVOF) WC-Co coatings which were used in the current investigation, are generally known to produce a relatively dense microstructure of superior sliding wear resistance [5]. This results from higher velocity and lower temperature of impacting lamellas during the thermal spray process. The former results in a denser microstructure, whereas the latter reduces carbon loss during the spraying process. Fracture behaviour shown in Fig. 8 also confirms that these coatings are relatively tougher when compared to APS coatings. Hence, the emphasis in the current investigation was to check if such an improvement in the coating microstructure could help combat cohesive and adhesive delamination, and improve the RCF performance of HVOF (JP5000) coatings. The results of RCF tests, designed to combat interfacial delamination, by shifting the orthogonal and maximum shear stress away from the coating substrate interface (tests T1-T8) are summarised in Table 2. It is to be appreciated from Table 2 (tests T1-T8) that none of the coated rolling elements, which had a coating thickness greater than the depth of maximum shear stress (approximately $80-115 \mu \mathrm{m}$ ), showed any delamination failure, either at the coating substrate interface or within the coating microstructure. Suspended tests T1 and T5 (Fig. 2a) also demonstrated that by appropriate control of coating thickness and lubrication regime (Table 2), it is possible to design thermal spray HVOF (JP5000) coatings to resist fatigue failure under moderate stress levels (up to $3 \mathrm{GPa}$ ). Although at stress levels in excess of $3 \mathrm{GPa}$, there was a failure of coatings, it needs to be appreciated that it was not a delamination failure. There was however, one exception, i.e. test T3, where cohesive delamination coupled with spalling (discussed below) contributed to the failure of this rolling element. This can be attributed to the mixed lubrication regime, which existed in all the tests conducted with Exxon-2389 as the test lubricant. Also, slightly higher frictional torque values, in general, were recorded with this lubricant. This was indicative of asperity contact and thus a small amount of tangential loading within the contact region. These factors, along with the possibility of a tiny flaw within the coating microstructure could have therefore, triggered delamination failure in test T3. The depth of subsurface cracks (Fig. 7) in this case was approximated as $100 \mu \mathrm{m}$, which is consistent with the approximate depth of maximum shear stress and typical of the mechanism of cohesive delamination in APS coatings, i.e. shear stress provides the driving force for subsurface crack initiation and propagation. However, in all other cases (tests T1-T8), either there was no failure, or the failed coated rolling elements indicated a new failure mode (i.e. spalling), rather than cohesive delamination, as discussed in Section 4.1.2. However, it can be appreciated that on the basis of tests T1, T2, T4-T6 and T8, that regardless of the changes in contact configuration, i.e. conventional steel or hybrid ceramic, HVOF (JP5000) coatings resisted coating delamination, as long as the coating thickness was greater than the depth of maximum shear stress, and a full film lubrication regime was maintained. The trend was consistent throughout the analysis, for the moderate stress levels (of around 2.7-3.7 GPa) considered in this investigation. This improvement in performance to resist delamination failure, in comparison with APS coatings, can be attributed to superior fracture behaviour (and microstructure) of HVOF coatings. 


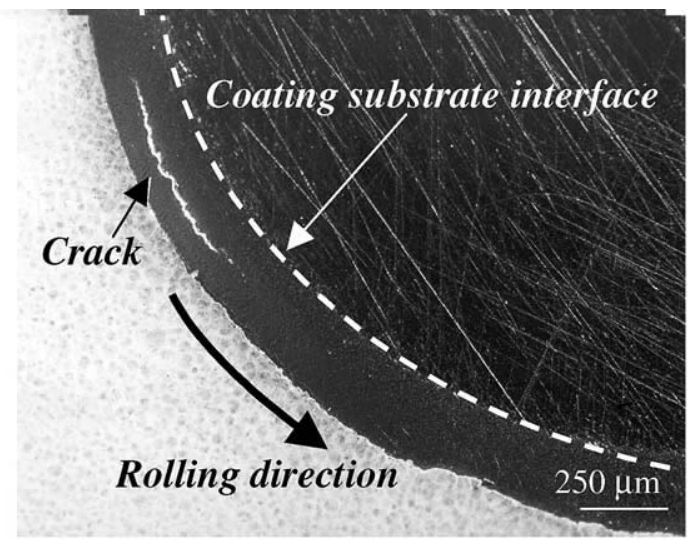

(a) Crack at approximate depth of $100 \mu \mathrm{m}$

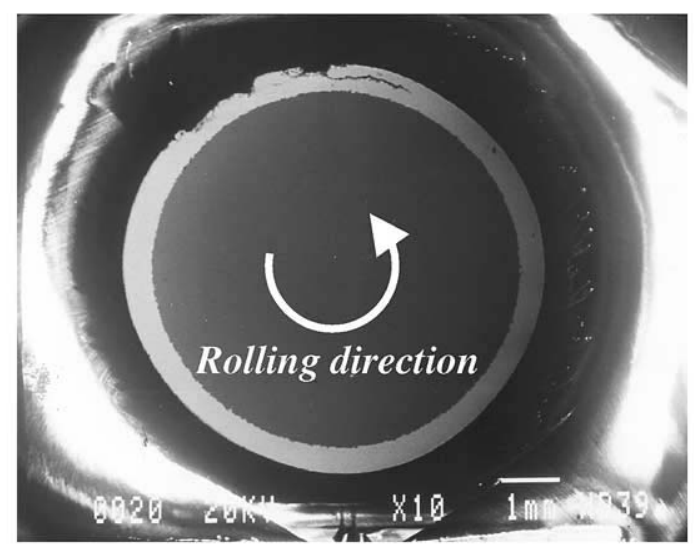

(c) SEM obervation of sectioned wear track

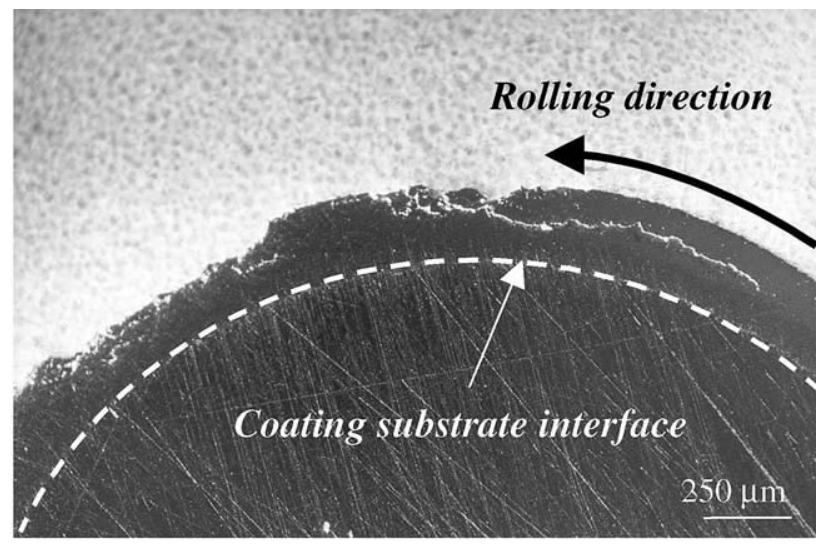

(b) Joining of cracks leading to delamination

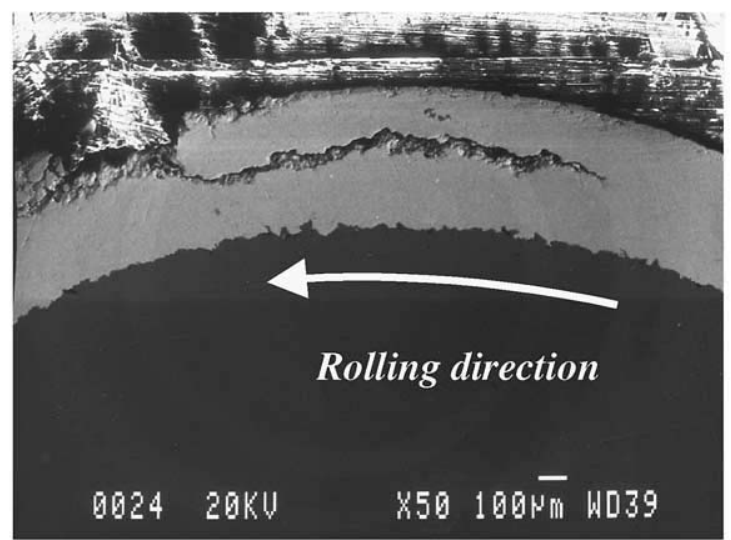

(d) Taper section across the wear track

Fig. 7. Subsurface crack observations (die penetrant) after test T3. (a) Crack at approximate depth of $100 \mu \mathrm{m}$; (b) joining of cracks leading to delamination; (c) SEM observation of sectioned wear track and (d) taper section across the wear track.

Contrary to this improvement in resistance to cohesive delamination, the resistance to adhesive delamination was marginally improved by the use of HVOF (JP5000) coatings, as discussed in the next section.

\subsubsection{Adhesive delamination}

For the case of thinner coatings (tests T9-T11), i.e. coatings in which coating thickness was equal to or less than the depth of maximum shear stress, the failure mode was adhesive delamination, i.e. delamination at the coating substrate interface, which occurred during the early stages of RCF tests. This trend was consistent, regardless of the changes in lubrication regime, stress level, or contact configuration. Fig. 6a shows the micrograph of a typical adhesive delamination failure, whereas Fig. $6 \mathrm{~b}$ shows sheet-like delamination debris. Adhesive delamination was a result of the migration of shear stress at or near the coating interface, which also resulted in poor RCF performance. This is consistent with the previous findings on APS coatings, where such coating thickness resulted in premature adhesive delamination. The mechanism of adhesive delamination in these relatively thinner HVOF coatings was thus consistent to what was previously reported for APS coatings, details of which can be seen in [3] and schematic of failure mechanism shown in Fig. 9, as discussed below.

To understand that why the location of shear stress (during contact loading) at or near the coating substrate interface is so catastrophic to drive crack initiation and propagation at this interface, we need to consider the coating substrate bonding mechanism of thermal spray coatings. Although, recently it has been argued that there is some degree of chemical bonding at the coating substrate interface, undoubtedly, the main mechanism of coating substrate bonding is mechanical interlock. This is optimised by shotblasting of substrate to improve the splat contact area, and also interlocking the splat on shotblasted asperities. Hence any contamination prior to spraying, wettability of impacting lamella, shadowing effects either due to angle of spraying or underlying lamellas, and quenching stress (microtensile) within the lamella, play an important role in dictating the coating substrate adhesive strength. There is thus inevitably a higher tendency of microdefects at the coating substrate interface. In the case of HVOF (JP5000) coatings, although the higher velocity and lower temperature of impacting lamella influence the coating microstructure and its properties (and thus improve cohesive strength), they do little 


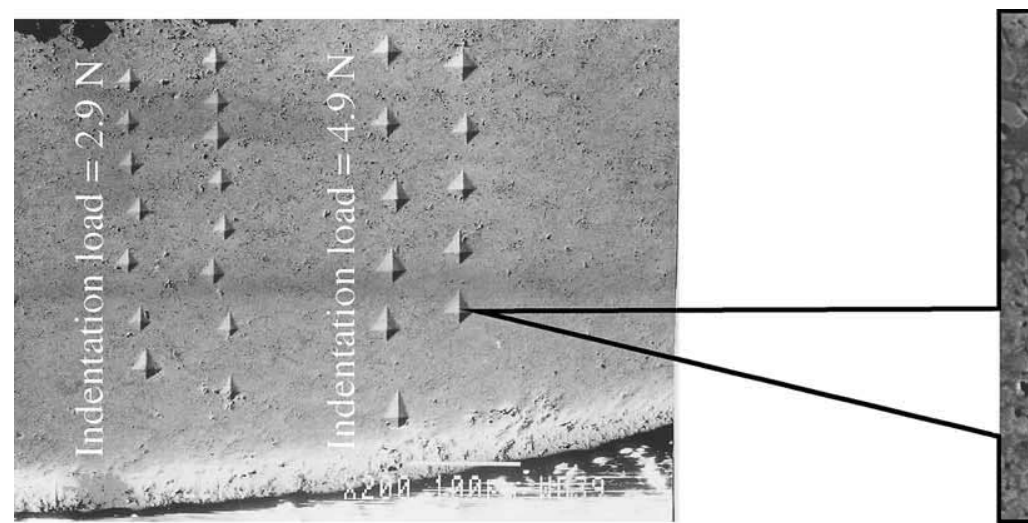

(a) Overall view across the coating thickness

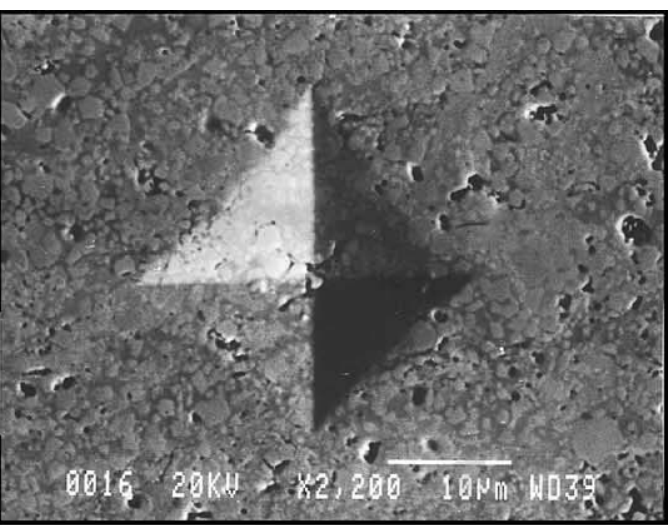

(b) Magnified view at $4.9 \mathrm{~N}$ load-no cracking

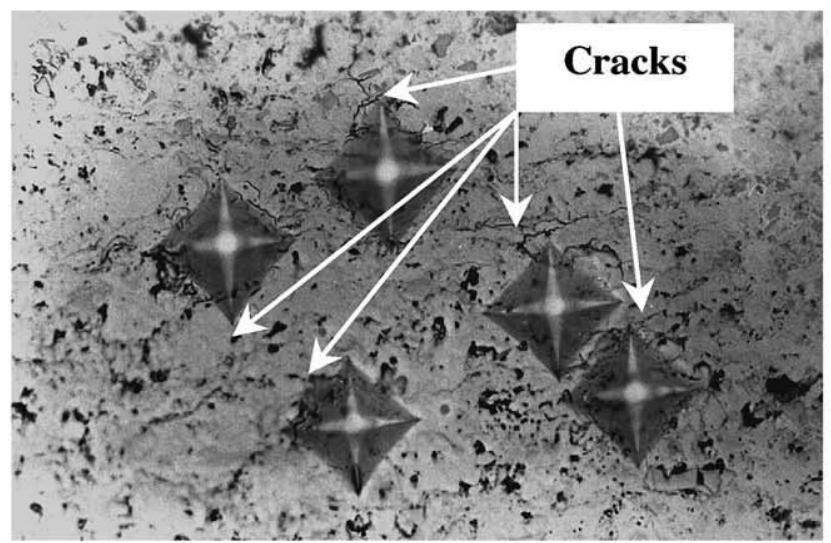

(c) Indentation behaviour of APS coating at indentation load of $2.9 \mathrm{~N}$

Fig. 8. Microhardness indentations across the coating thickness at loads of 2.9 and 4.9 N. (a) Overall view across the coating thickness; (b) magnified view at $4.9 \mathrm{~N}$ load-no cracking and (c) indentation behaviour of APS coating at indentation load of 2.9 N [3].

to improve the adhesive strength of coating. This, coupled with the fact that there is always some elastic mismatch at the coatings substrate interface inevitably results in adhesive delamination, if the driving force for crack initiation and propagation, i.e. maximum shear stress, is located at the coating substrate interface. However, as this driving force, i.e. shear stress is moved away from the coating substrate interface, e.g. by increasing the coating thickness, adhesive delamination can be avoided for moderate stress levels (of around 2.7-3.7 GPa), considered in this investigation.

The above discussion, however, poses a critical question, that if there is a mismatch of coating substrate elastic modulus, the stress field will not be Hertzian, and thus optimum thickness of coating to push the shear stress away from the interface could not be readily approximated. Various investigations have addressed this problem of stress distribution in layered structures, either by using finite element modelling (FEM) or mathematical formulation using integral transfer technique [11-14]. Such investigations have revealed that for small mismatch of coating substrate elastic properties, the stress field can be approximated as Hertzian. For elastic modulus measurements in thermal spray coatings, it is generally understood that the elastic modulus of sprayed ma- terial is approximately one-third of the bulk material. For thermally sprayed WC-Co coatings, there is no exception to this rule, and Brent [15] has shown that the value of Young's modulus in thermally sprayed HVOF WC-12\%Co coatings is around $240 \mathrm{GPa}$. This is consistent with the above generalisation of one-third rule, from which, Young's modulus for WC-12\% Co coatings can be approximated as $220 \mathrm{GPa}$. Although, the measurement of Young's modulus in thermal spray coatings is dependent upon the method and direction of measurement, the above approximation of 200-240 GPa for $\mathrm{WC}-12 \mathrm{Co} \%$ coatings is generally consistent with other published literature [16]. Also, the value of Young's modulus measured by the indentation technique, as indicated in Section 3.3, had a similar range of $231 \pm 17 \mathrm{GPa}$. Thus, it can be appreciated that the ratio of coating to substrate Young's modulus is almost unity for the case of WC-12\% Co (HVOF) coatings deposited on a 440-C bearing steel substrate, and hence the stress field can be approximated as nearly Hertzian; though there will be a slight elastic mismatch at the interface, leading to stress concentrations and subsequent crack initiation and propagation. The experimental test results (Table 2) confirm such a trend of failure dependence on coating thickness, and a factor of safety thus needs 


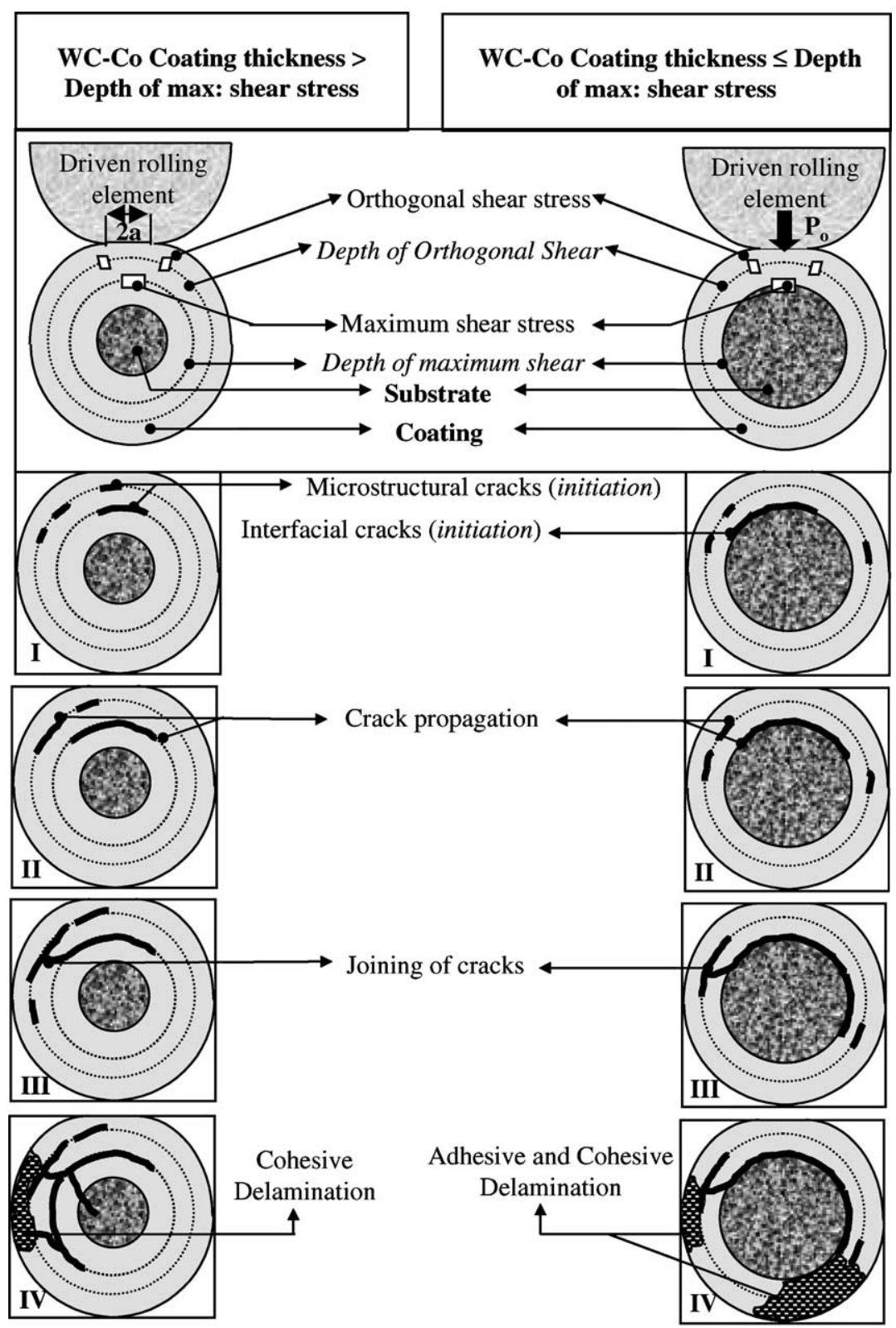

Fig. 9. Schematic of coating delamination process for WC-Co coatings extracted from Ref. [3]. I: Crack initiation at depths of maximum and orthogonal shear; II: crack propagation's parallel to surface; III: combination of cracks and IV: delamination.

to be incorporated in approximating the minimum coating thickness to avoid adhesive delamination, as discussed in Section 4.2.

\subsubsection{Spalling}

A spall type failure, which is typical of fatigue failure in bearing steels, was also observed in thermal spray HVOF (JP5000) coatings. SEM observation of this failure for the RCF test T4 is shown in Fig. 5. Profilometric analysis of this spall indicated that the spall dimensions were similar to those observed in homogenous bearing materials [17,18], which is generally defined as a sharp edged steep walled flat bottom feature, formed by the fracture of surface (Fig. 10). Similarly,
Tallian [18] has described "spalling" as macroscale contact fatigue damage, leading to macroscopic craters within the contact region at a depth comparable to maximum Hertzian shear stress. A typical comparison of fatigue spall in thermal spray coatings (Fig. 5a) to the fatigue spall in bearing steel can be made by comparing Figs. 5a and 10. Other terminologies, such as macropitting, to describe fatigue spalling in bearing steels have also been used in published literature. The terminology of spall has, however, been used in this article. This failure mode is much different from the delamination failure (either cohesive or adhesive) generally seen in thermal spray coatings. A spall type of failure can be differentiated from delamination type failure by 


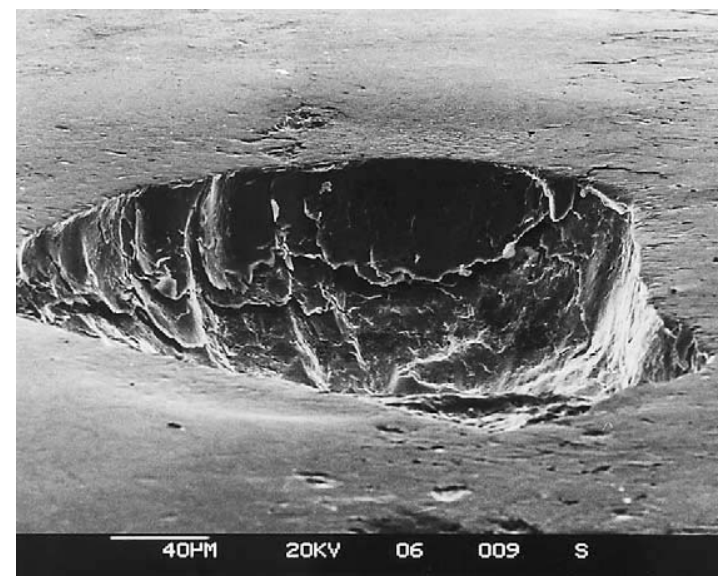

Fig. 10. Contact fatigue spall within the wear track of a 440-C bearing steel rolling element ball.

considering the area to depth ratio of failure. Delamination in thermal spray coatings results in sheet-like debris (Fig. 6) of much greater surface area than a fatigue spall. Also, spall is localised within the wear track, whereas delamination in thermal spray coatings generally extends beyond the width of wear track. Spalling type of failure mode is, however, rare in thermal spray coatings and can be attributed to the fact that that the coatings under investigations produced by a JP5000 system had a relatively higher indentation toughness (Fig. 8) than the APS coatings. This change in fracture resistance could trigger the failure mode to alter from cohesive delamination to spalling.

\subsubsection{Mechanism of spalling}

Although the full extent of the failure mechanism leading to this failure mode (spalling) in HVOF (JP5000) coatings is not completely understood at this stage, it is appreciated that it could have been caused by surface microcracking, either due to the asperity contact, or tensile cracking at the edge of contact region, followed by crack propagation either in shear mode, i.e. shear stress at the crack tip, or due to lubricant entrapment mechanism [19]. Similarly, the possibility of subsurface to surface cracking can also not be excluded at this stage.

One of the major causes of spalling in conventional bearing steels is thought to originate from the Way's hypothesis of lubricant entrapment [19]. In the case of thermal spray coatings, post-RCF observations of failed coated rolling elements although did provide some evidence of the possibility of lubricant entrapment mechanism of crack propagation for low viscosity Exxon-2389 lubricant (Fig. 4b), there was no such evidence seen for the high viscosity Hitec-174 lubricant. If, however, it is assumed that the crack initiation and propagation direction was surface to subsurface, then the orientation of cracks (Figs. $4 \mathrm{~b}$ and $7 \mathrm{~b}-\mathrm{d}$ ) with respect to the rolling direction, are indeed in agreement to support Way's [19] theory of lubricant entrapment hypothesis of crack propagation, i.e. hydraulic pressure propagation (HPP). The failure in these cases (Figs. $4 \mathrm{~b}$ and $7 \mathrm{~b}-\mathrm{d}$ ) was, however, delamination and not spalling. Similarly, considering the high viscosity of Hitec-174 lubricant (Table 1), the possibility of such mechanism of crack propagation seems remote, as there would not have been sufficient low lubricant viscosity to support this mechanism. Also, although not observed in the case of spalling failure, but the cracks leading to delamination failure, e.g. in Fig. 4b, extends beyond the width of the wear track. This meant that the crack lip would not have been adequately sealed to generate significant pressure for cracks to propagate viz. HPP hypothesis. Hence in view of above observations, the probability of HPP leading to spalling of thermal spray coatings seems remote. Post-RCF failure examination of spalled coating in Fig. 5 indicates micropitting within the wear track. This indicated that micropitting could have initiated surface to subsurface crack propagation, leading to spalling in thermal spray coatings. Other modes of crack propagation both from surface to subsurface or subsurface to surface, however, also need to be explored to fully understand the mechanism of spalling in thermal spray coatings.

To understand why was there no spalling failure observed in previously reported APS coatings, we need to consider the mechanism of coating build-up during thermal spraying. Although advancements in thermal spray technology, such as HVOF liquid fuel radial injection systems, and a through understanding of the influence of start powder and coating process parameters $[5,20]$ have enabled the coating microstructure with negligible porosity and secondary phase content, the possibility of micro-cracking due to quenching residual stress (micro-tensile) and poor bonding at the interface of unmelted or partially melted particles exist within the coating microstructure. These defects can act as stress risers and can thus promote both subsurface and surface crack initiation (and propagation). Hence, although in the case of HVOF (JP5000) coatings, delamination failure can be resisted by appropriate design, spalling, which in conventional bearing steels is though to arise from subsurface or near surface defects, can be triggered at the location of microstructural defects within thermal spray coatings. However, further studies are inevitable to fully understand this failure mechanism in thermal spray coatings.

\subsubsection{Abrasion}

For most of the cases of coating failure in which thickness was greater than the depth of maximum shear stress, micropitting (abrasion) was the dominant failure mode. Abrasive failure in thermal spray coatings can be associated with asperity contact, coupled with microslip within the contact region. This type of failure was thus imminent, especially with ceramic planetary balls (test T2, T6), which were harder than the coating material. Comparison of Fig. 2a and b distinguish the influence of higher hardness of ceramic planetary balls and indicate that this hardness difference can seriously influence the performance of these coatings. When lubrication conditions were in the mixed 
regime (with Exxon-2389 lubricant), the mechanisms of two- and three-body abrasion thus dominated abrasive failure. The profilometric analysis (Fig. 3) of the wear track indicated that the depth of micro-pits associated with this failure mode was up to $10 \mu \mathrm{m}$, which was consistent with the debris analysis from these tests, and indicative of the WC particle pullout caused by the microfracture within the coating material. The mechanism of coating abrasion was thus similar to what was observed in APS coatings [3], i.e. asperity contact in the presence of microslip within the contact region, and can be understood for the tests conducted with Exxon 2389 as the test lubricant, i.e. where lubrication regime was mixed. Once initial wear debris were produced, three-body abrasion further accelerated the process.

However, albeit full film lubrication $(\lambda>3)$ for Hitec-174 lubricant, abrasion was also observed on the surface of wear track with this lubricant, especially with ceramic planetary balls. Although the presence of wear debris within the contact region could explain the mechanism of abrasive wear, i.e. three-body abrasion, even in full film regime, it requires an understanding of how could the initial wear debris be generated in full film regime? Three possibilities are thought to have contributed to the generation of initial wear debris in full film regime. The first two possibilities deal with the possibility of asperity contact, whereas the third possibility deals with the microfracture within the coating material. Firstly, at the start of each test, lubrication regime passes through the mixed region, before full film is established. There is thus a possibility of asperity contact at the start of RCF test. Secondly, although the $\lambda$-values approximated for the range of tribological test conditions, were approximately in the range $\lambda=4-5$, these values are based upon the RMS surface roughness of coated rolling elements. The peak to valley roughness of surfaces, in general, is indeed greater than the RMS surface roughness, and hence few peaks above the RMS value could have initiated the asperity contact. To check both of these effects, the surface of rolling elements which failed within first few hundred cycles of testing were examined. There was indeed some evidence of micropitting and dents within the wear track. However, this could be a post-failure damage, caused by the delamination debris. But for now, even if it was assumed that the above two possibilities were the main contributors of abrasive wear initiation in full film regime, it does not explain why abrasive wear was more common in hybrid ceramic configuration tests, and also in conventional steel configurations tested at higher stress of around $3.7 \mathrm{GPa}$. To address this point, we need to consider the possibilities of tensile fracture on the surface of wear rack.

Apart from the mechanism of asperity deformation leading to micropitting of coating surface, the criterion of maximum tensile stress at the edge of contact area for brittle materials (such as thermally sprayed cermet coatings) thus also need to be considered. Maximum tensile stress $\left(T_{\max }\right)$ is very sharply localised around the edge of contact region, and decay very rapidly at small depths below the surface. For elliptical contacts, this tensile stress $\left(T_{\max }\right)$ for a given value of peak compressive stress $P_{\mathrm{o}}$ can be evaluated from the following relation reproduced here for clarity (ESDU-84017) [8]:

$$
\frac{T_{\max }}{P_{\mathrm{O}}}=\frac{0.33 \beta}{n^{3}}\left[0.5 \ln \left(\frac{1+n}{1-n}\right)-n\right]
$$

where $\beta$ is the ratio of minor to major axis of contact ellipse, and $n=\left(1-\beta^{2}\right)^{0.5}$. For the test conditions used in the test programme, $T_{\max }$ was approximated as $324 \mathrm{MPa}$ at a contact stress $\left(P_{\mathrm{o}}\right)$ of $2.7 \mathrm{GPa}$. Tucker [21] have shown that the fracture stress of $\mathrm{WC}-\mathrm{Co}$ coatings using the technique of tensile test (free standing ring) is in the range 380-690 MPa for HVPS and D-Gun coatings. These values of tensile fracture stress are similar to the tensile stress associated with the Hertzian stress distribution at the edge of the contact region. This indicates that even under fully developed EHL $(\lambda>3)$ regime, the microcracks in the coating material, either due to coating defects or asperity contact can propagate due to tensile stress at the edge of the contact area. Hence, coating fracture toughness also needs to be considered along with other tribological test conditions whilst combating coating's abrasive failure. The quantitative analysis of fracture behaviour between HVOF (JP500) and APS coatings shown in Fig. 8 indicated relatively improved toughness of HVOF coatings; it was thus not surprising to note that at stress levels of around $2.7 \mathrm{GPa}$, HVOF coatings did not show abrasive failure. Contrary to this, RCF tests performed under similar conditions of contact stress (of $2.7 \mathrm{GPa}$ ), configuration and lubrication for APS coatings indicated significant micropitting (abrasive wear) on the surface of wear track [3]. However, even for HVOF (JP5000) coatings, as the stress level increased beyond $2.7 \mathrm{GPa}$ (in the current investigation), abrasive failure was observed, indicating the limit beyond which, abrasive failure occurs even in HVOF (JP5000) coatings.

The process of abrasive wear was found to accelerate at the later stages of RCF test due to the introduction of initial wear debris into the contact region, leading to three-body abrasion. Small-sized wear debris were produced during this process. This is consistent with the previous findings on APS coatings, where filtering and recirculation of lubricant reduced the intensity of abrasive wear. Dents were also seen in the wear track at advanced stages of tests, which confirmed the presence of debris in the contact region. It is worth appreciating that three-body abrasion influenced the rate of micropitting for tests in both conventional and hybrid ceramic configurations because the wear debris were predominantly that of coating material and hence, of similar or higher hardness (due to flash temperature) to that of contacting pair. The specific analysis of the influence of size, shape and composition of coating debris within the rolling contact region on micropitting of thermal spray coatings was however beyond the scope of this work and, readers are referred to work by Sayles [22] to appreciate these factors. 


\subsection{Performance vs coating thickness and contact stress}

All coated rolling elements which had an average coating thickness of $50 \mu \mathrm{m}$ (tests T9-T12), failed by interfacial delamination (Fig. 6), regardless of the changes in contact configuration, Hertzian stress field and lubrication regime. This type of failure mode was thus dependent upon the coating thickness and thus the location of shear stress at or near the coating substrate interface. Table 2 gives an indication of the coating performance under various tribological conditions. Although these results do not provide the basis for a statistical analysis, it can be appreciated that at contact stress levels of $2.7 \mathrm{GPa}$, coatings which had a thickness greater than the depth of maximum shear stress (tests T1 and T5) showed a fatigue life in excess of 50-70 million stress cycles, without failure in full film regime. In the case of hybrid ceramic configuration, although the performance was not as high as with conventional steel configuration, there was no delamination failure. Contrary to this, in the rolling elements where coating thickness was less than or equal to the depth of maximum shear stress, coatings failed catastrophically and instantaneous due to adhesive delamination. As discussed earlier, this was mainly due to the location of maximum shear stress at the coating substrate interface, which provided the driving force to initiate and propagate delamination cracks. This was also consistent with the findings of thinner APS coatings reported earlier [3]. Hence on the basis of current and also previous [3] investigations, it can be concluded that regardless of the changes in coating process, i.e. either APS or state of the art JP5000 coatings (used in the current investigation), coating thickness plays a key role in combating interfacial delamination. The advantage of HVOF system in caparison to APS system is thus only realised in terms of resistance to cohesive delamination, i.e. when coating thickness is greater than the depth of maximum shear stress, but not in terms of resisting adhesive delamination. This behaviour of resistance to delamination was consistent regardless of the changes in contact configuration, i.e. conventional steel or hybrid ceramic. It was thus possible to relate the coating performance to resist delamination failure and contact stress conditions by non-dimensional coating thickness $(\Delta)$, defined as follows:

$\Delta=\frac{\xi}{\Psi}$

where $\xi$ is the coating thickness and $\Psi$ the depth of maximum shear stress (Table 2). Results of this analysis are shown in Fig. 11, which indicates that for the values of $\Delta$ greater than 1.5 , contact stress dominates the performance of coated rolling elements for each contact configuration, and the influence of coating thickness was minimal. This can also be confirmed by the absence of interfacial delamination failure mode for the tests in which $\Delta>1.5$. Although for stress levels greater than $3 \mathrm{GPa}$ and $\Delta>1.5$, it was not possible to match the RCF performance of 70 million stress cycles without failure, the results are consistent with the above conclusion, as the main failure mode was abrasion, which is neither catastrophic nor instantaneous, but progressive. It is worth appreciating that the location of shear stress to evaluate various values of $\Delta$ in the above analysis were based upon Hertzian theory, as the ratio of coating to substrate Young's modulus was around unity, and the coatings were thick, so that the contact stress fields were located away from the coating substrate interface. However, if the analysis was to be extended to other coating and materials, especially where the modulus ratio is greater, a factor of safety for appropriate value of $\Delta$ needs to be incorporated.

Finally, in the above analysis and discussion, the depth of maximum shear stress is used instead of orthogonal shear stress to combat adhesive delamination. This was due to the fact that, although the range of orthogonal shear stress (total magnitude) is greater than that of maximum shear

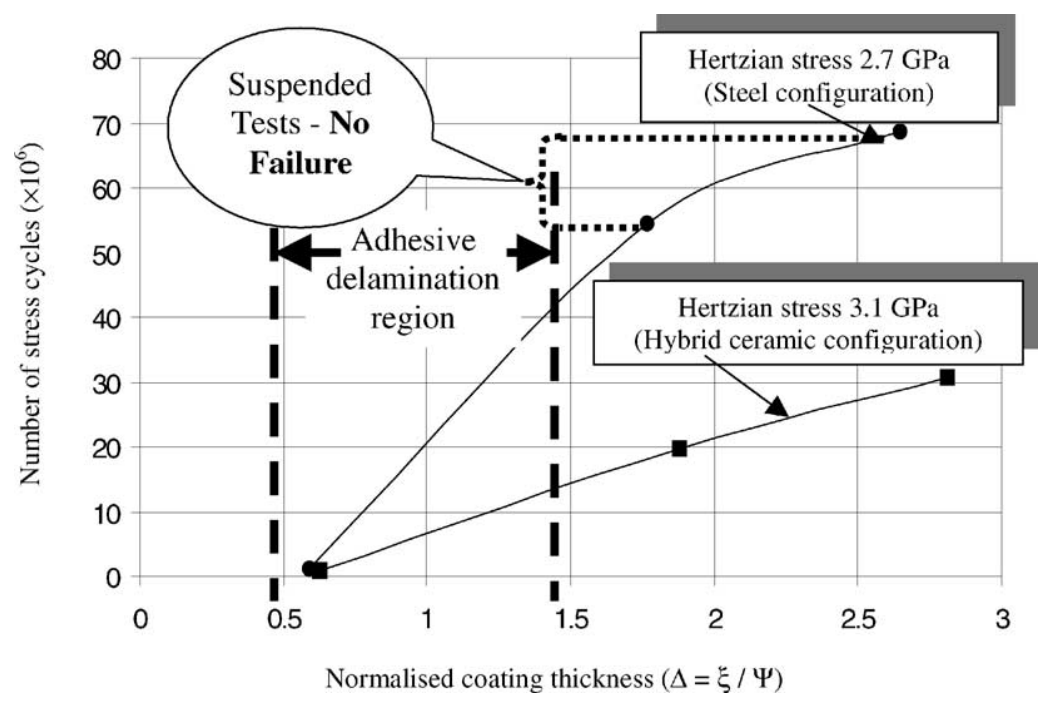

Fig. 11. Influence of normalised coating thickness on stress cycles in full film regime $(\lambda \geq 3)$. 
stress, orthogonal stress occurs at relatively shallower depth from the surface in comparison to maximum shear stress. Hence, whilst designing the minimum coating thickness to combat delamination, the depth of maximum shear stress provides a much better (and safer) estimate of minimum coating thickness than that based upon the orthogonal shear stress.

\section{Conclusions}

On the basis of above discussion, it can be concluded that:

1) It is possible to combat interfacial delamination of thermally sprayed cermet (WC-Co) coatings by appropriate selection of coating thickness, and a non-dimensional coating thickness parameter, i.e. $\Delta \geq 1.5$ can be used as a semi-empirical guide for coating design.

2) RCF investigations of the HVOF (JP5000) coatings indicate that by appropriate control of coating thickness $(\Delta \geq 1.5)$, and tribological conditions of contact stress $\left(P_{\mathrm{O}}<2.7 \mathrm{GPa}\right)$ and lubrication regime $(\lambda>3)$, it is possible to achieve a fatigue life in excess of 70 million stress cycles without failure.

3) In addition to previously reported contact fatigue failure modes of coating delamination and abrasion in APS coatings, a new failure mode, i.e. spalling was observed in thermally sprayed HVOF coatings. This was attributed to improved fracture toughness of these coatings.

\section{Acknowledgements}

Author is grateful to Dr. D. Scherer at the Institute for Manufacturing Technologies of Ceramic Components and Composites, University of Stuttgart, Germany, for Young's modulus measurements in thermal spray coatings.

\section{References}

[1] A. Nakajima, T. Mawatari, M. Yoshida, K. Tani, A. Nakahira, Effects of coating thickness and slip ratio on durability of thermally sprayed WC cermet coatings in rolling/sliding contact, Wear 241 (2000) 166173 .

[2] B.Y. Sarma, M.M. Mayuram, Some studies on life prediction of thermal sprayed coatings under rolling contact conditions, ASME J. Tribol. 122 (3) (2000) 503-510.
[3] R. Ahmed, M. Hadfield, Failure modes of plasma sprayed WC-Co coated rolling elements, Wear 230 (1999) 39-55.

[4] R. Ahmed, M. Hadfield, Influence of coating thickness and contact stress on the fatigue failure of HVOF coatings, in: Proceedings of the International Thermal Spray Conference, Singapore, 2001, pp. 1009-1015. ISBN 0871707373.

[5] R. Schwetzke, H. Kreye, Microstructure and properties of tungsten carbide coatings sprayed with various HVOF spray systems, J. Thermal Spray Technol. 8 (3) (1999) 433-439.

[6] R. Tourret, E.P. Wright, in: Proceedings of the International Symposium on Rolling Contact Fatigue: Performance Testing of Lubricants, Inst. Petroleum, October 1976, Heyden, London, 1977.

[7] B.O. Jacobson, Rheology and Elasto-hydrodynamic Lubrication, Baker \& Taylor, 1991.

[8] Contact phenomena. II. Stress fields and failure criterion in concentrated elastic contacts under combined normal and tangential loading, Engineering Science Data Units, ESDU-84017, 1984.

[9] C.K. Lin, C.C. Berndt, Measurement and analysis of adhesion strength for thermally sprayed coatings, J. Thermal Spray Technol. 3 (1) (1994) 75-104.

[10] M. Buchmann, M. Escribano, R. Gadow, D.G. Bürkle, M. Mahlich, H.J. Fecht, On the elastic mechanical properties of thermally sprayed coatings, in: Proceedings of the International Thermal Spray Conference, Essen, Germany, Manuscript Number 244, 2002.

[11] P.K. Gupta, J.A. Walowit, Contact stress between an elastic cylinder and a layered elastic solid, Trans. ASME (1974) 250-257.

[12] S.J. Cole, R.S. Sayles, A numerical model for the contact of layered elastic bodies with real rough surfaces, Trans. ASME 114 (1992) 334-340.

[13] H. Djabella, R.D. Arnell, Finite element analysis of the contact stresses in an elastic coating on an elastic substrate, Thin Solid Films 213 (1992) 205-219.

[14] R. Ahmed, M. Hadfield, Fatigue behaviour of HVOF coated M50 steel rolling elements, Surf. Eng. 14 (6) (1998) 473-480.

[15] O.C. Brandt, Mechanical properties of HVOF coatings, J. Thermal Spray Technol. 4 (2) (1995) 147-152.

[16] Powlowski, The science and engineering of thermal spray coatings, 1995. ISBN 0-471-95253-2.

[17] T.E. Tallian, On competing failure modes in rolling contact, Trans. ASLE 10 (1967) 418-439.

[18] T.E. Tallian, Failure atlas for Hertz contact elements, 2001. ISBN 0-7918-0084-9.

[19] E. Way, Pitting due to rolling contact, J. Appl. Mech. 2 (1935) A49-A58.

[20] H.L. Villers Lovelock, Powder/processing/structure relationships in WC-Co thermal spray coatings: a review of the published literature, J. Thermal Spray Technol. 7 (3) (1998) 357-373.

[21] R.C. Tucker, Structure property relationship in deposits produced by plasma spray and detonation gun techniques, J. Vac. Sci. Technol. 11 (1994) 725-734.

[22] R.S. Sayles, Debris and roughness in machine element contacts: some current and future engineering implications, J. Eng. Tribol. 209 (3) (1995) 149-172. 